\title{
DEL TÉRMINO 'POETISA’: ACEPTACIONES Y REPULSAS
}

JOSÉ MARÍA BALCELLS

Universidad de León

En las últimas décadas se asistió a una polémica más o menos áspera a propósito de la denominación de "poeta" o "poetisa" referida a las mujeres que componen poesía en España. Pero la controversia sobre dichas denominaciones aplicadas a la creación poética de las autoras no es un fenómeno nuevo en la cultura literaria española, pues sus antecedentes próximos ya se dejaban sentir incluso antes de los treinta, como lo ilustran unas palabras de Ernestina de Champourcin, quien en el umbral de esos años, en concreto en 1929, afirmaba sobre las mujeres que escriben poesía que

son únicamente poetas, como sus colegas masculinos, poetas, claro está, buenos o malos, igual que ellos (...) No es necesaria una palabra distinta para apreciar las diferencias de sexo (Landeira, 2005: 72).

Esta convicción la reiteraba al final de las líneas que, a propósito de su vida, redactó para la antología de Gerardo Diego Poesía española. Antología (Contemporáneos)(1934), donde asegura:

En la actualidad no puedo oír mi nombre, acompañado por el horrible calificativo de poetisa, sin sentir vivos deseos de desaparecer, cuando no de agredir al autor de la desdichada frase (Diego, 2007: 240).

Esta opción de repulsa de la poeta de Vitoria seguiría actuante a mediados del siglo $\mathrm{XX}$, como señaló en su día Dámaso Alonso en una generalización que, por otra parte, resultó entonces excesiva: “A las mujeres españolas que escriben hoy en verso parece que no les gusta que se las llame 'poetisas': se suelen llamar, entre sí, 'poetas' "(Alonso, 1952: 339).

Cabría apostillar que algunas escritoras no se limitaban a oponerse, en privado y entre ellas, al término "poetisa", sino que se opusieron a él públicamente, como lo atestigua el principio de la composición de Gloria Fuertes “¡Hago versos, señores!”, perteneciente a Todo asusta: “Hago versos, señores, hago versos,/ pero no me gusta que me llamen poetisa,/ me gusta el vino como a los albañiles..." (Fuertes, 2004: 91). La gaditana Pilar Paz Pasamar expresaría este mismo sentir en una entrevista: "Soy una mujer poeta. Poetisa me parece una palabra detestable que la Real Academia debería prohibir" (Crespo, 1964: 24).

Federico de Onís daba una explicación al hecho de que a distintas autoras les resultase repelente ser denominadas 'poetisas': "ellas gustan de llamarse 'poetas' para diferenciar un poco su libertad expresiva actual de la antigua poesía femenina" (Onís, 1965: 247).

Distanciarse de la denominación de "poetisa" no conlleva que esa palabra tenga que ser denostada de modo expreso, porque basta con optar, en la práctica, por el vocablo "poeta", como en el texto de Ana María Fagundo 
"Canto a Canarias", de su conjunto El sol, la sombra, en el instante (1994), composición que culmina con los siguientes versos:

Conmigo estáis, islas de mi niñez, islas de mi adolescencia,

islas de mi vida toda.

Conmigo estáis

porque yo soy vuestra isla en punta, porque yo soy vuestra presencia en la ausencia, porque yo soy vuestra poeta.

(Facundo, 2002: 255).

Autoras de promociones de fines del XX se han referido también a sí mismas como "poetas", no como "poetisas", tal como atestiguan sendos pasajes sobre poética personal de Josefa Parra y Luisa Castro. La primera decía:

Y mi objetivo es provocar el mismo deleite que he recibido en quien me lee, sin conocerme, sin saber si soy hombre o mujer, zurda o diestra, malvada o angelical. Si mis palabras son capaces (al menos de vez en cuando) de hacer el prodigio, será que aquella elección temprana no era tan arriesgada, y que puedo poner en mis documentos, sin demasiado sonrojo, 'de profesión: poeta' (Benegas \& Munárriz, 1997: 599).

La siguiente declaración corresponde a la segunda:

Yo formo parte del mundo y, por tanto, lo que escribo no es algo aislado. Creo que soy una poeta que alterna las dos tendencias actuales con esos dos nombres tan cursis (experiencia y diferencia) de un modo bastante natural... (Benegas \& Munárriz, 1997: 610).

Además de las mencionadas, otra manera de oposición al término iba a ser, con el tiempo, la paródica, como en uno de los momentos del libro segundo de la canaria Tina Suárez Rojas, Pronóstico reservado. Los versos aludidos pertenecen al texto "Confidencias", con el que se abre el conjunto. Obsérvese la ridiculización a la que la autora somete no sólo a "poetisa", sino a otras palabras asociadas, y también desvalorizadoras:

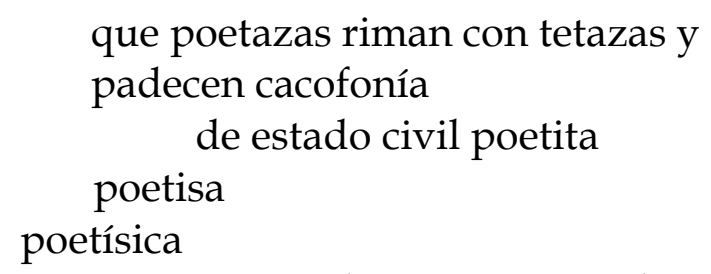

(Suárez, 1998: 15)

Pero tampoco ha de olvidarse que el empleo de "poetisa" no siempre tradujo conceptos desvalorizadores. Y buena prueba de ello fue su utilización por Enrique Díez- Canedo, quien usaba habitualmente dicho sustantivo para 
referirse a escritoras de la talla de Delmira Agustini, Juana de Ibarbouru, Gabriela Mistral, Alfonsina Storni y Rosalía de Castro, a todas las cuales, en verdad, la adscripción al término no parece haber menoscabado su general reconocimiento literario. La serie de artículos del referido crítico al respecto ("Poetisas, I", "Poetisas, II", "Poetisas, III" y "Más poetisas"), que se publicaron en 1923,1 demuestran también que el empleo de "poetisa" nunca desapareció, como es obvio, y por ende seguiría valiendo, en positivo, en décadas subsiguientes.

Y es que, por la época en que Dámaso Alonso hizo la observación de la que dimos cuenta un poco más arriba, Ángela Figuera publicaba en Espadaña el poema "Exhortación impertinente a mis amigas poetisas", ${ }^{2}$ instándolas hacia una poética de compromiso social. Pueden servir como muestra de que el vocablo no periclitó tanto los usos académicos como diversos títulos de compilaciones antológicas. Entre los primeros recuerdo, como ilustración, el epígrafe de Ángel Valbuena Prat "Las poetisas: De la Torre, Champourcin, Concha Méndez de Altolaguirre", dentro de su Historia de la literatura española, publicada por vez primera en 1937. ${ }^{3}$ Entre los segundos, anotamos la antología de Carmen Conde Once grandes poetisas americohispanas, una recopilación con comentarios, y que vio la luz en Madrid, en 1967. Lustros después aparece Las primeras poetisas en lengua castellana, edición preparada por Clara Janés, y publicada en Madrid en 1986. También hay que recordar la serie de ellas iniciada por Luzmaría Jiménez Faro en 1987 bajo el lema Poetisas españolas, y la que editaría Emilio Miró en 1999 bajo la titulación de Antología de poetisas del 27.

En alguno de los ejemplos recién citados, el empleo de "poetisa" significaba reafirmarse en el uso secular. En otros casos, en cambio, valerse del término suponía la "recuperación" del mismo desde una actualizada perspectiva, en convergencia con palabras como las siguientes de Balbina Prior:

...algunas poetisas pertenecientes a las nuevas generaciones sin complejos hemos decidido poner fin a esa travesía de penalidades, por cierto, todavía no advertida por numerosos poetas varones. Se está tratando de recuperar el antiguo nombre de 'poetisa', denostado durante tanto tiempo. (Prior, 2002: 33-34).

Por lo demás, en el siglo XIX ya se habían producido disputas varias al respecto de las palabras "poeta" y "poetisa", como veremos después. Con todo, parece excusado añadir que los puntos de vista esgrimidos en cada época han sido diferentes, e incluso que se han defendido ópticas muy atípicas, siendo una de las más singulares, ¿cómo no?, la que puso Miguel de Unamuno en labios de Macedo, en el Acto segundo, escena II, de obra dramática Sombras de sueño, editada por primera vez en 1927. Dicho personaje no estaba a favor del empleo de "poetisa" porque, caso de emplearse, correlativamente a los hombres habría

\footnotetext{
${ }^{1}$ Para más información sobre estos artículos, se remite a Marcelino Jiménez León. "La poesía escrita por mujeres hispanoamericanas y las críticas de Enrique Díez-Canedo en la revista España", en Literatura de las Américas (1898-1998). José Carlos González Boixo, Javier Ordiz Vázques y María José Álvarez Maurín, coordinadores. León: Universidad, 2000, 797-801.

${ }^{2}$ Cf. Espadaña (Poesía y crítica) 45 (1950).

${ }^{3}$ La Historia de la literatura española de Ángel Valbuena Prat tuvo su primera edición, en efecto, en 1937, siendo reeditada en numerosas ocasiones desde entonces.
} 
que llamarles "poetos". Él defiende el uso de "poeta" tanto para ellos como para ellas, y así dice: "No me gusta eso de poetisa...Hombre poeta, mujer poeta" (Unamuno, 1998: 60).

\section{Justificación idiomática de "poetisa"}

Como era presumible, no ha faltado quien entienda que no resulta de recibo prescindir de las diferenciaciones terminológicas tradicionales. Entre los que así sienten, se cuentan quienes alegan razones en gran medida idiomáticas, y aún eufónicas 4 . Aduciré un par de alegatos en pro de "poetisa" desde la vertiente del lenguaje mismo. El primero lo firmaba la poeta y antóloga Luzmaría Jiménez Faro, la cual puso al frente de una de sus realizaciones recopilatorias una “Justificación" en la que se lee:

A estas alturas me resulta un tanto absurda la manía de llamar 'poetas' a las mujeres que escriben poesía: si lo que queremos es una reivindicación y un reconocimiento (como ocurre con las 'catedráticas', las 'juezas', o las 'ministras'), no hay por qué acudir a una masculinización que nos equipara, sino al mantenimiento de un término que nos personaliza y distingue. El día en que la hermosa palabra poetisa no nos suene a algo cursi o decimonónico, nuestra batalla habrá sido ganada... (Jiménez Faro, 1987: 24).

Muy atendible resulta el argumento de Jiménez Faro, aunque apostillaremos que de la tacha de cursilería asociada a la voz "poetisa" no suelen tener responsabilidad alguna las autoras, y tampoco la "masculinización" a la que alude está en el ánimo de las que prefieren ser llamadas "poetas", pues lo que se reivindica es neutralizar una visión minusvalorizadora de la poesía escrita por mujeres al amparo de una palabra, la de "poeta", que no conlleva tal lastre.

En parecida línea de objeción a la de Jiménez faro se sitúa el poeta Enrique Badosa, el cual escribió un epigrama a vueltas de dicho asunto:

Quieres que te llame "la poeta", y por lógico impulso feminista llevar al unisex la profesión. A mí lo de "poeta" no me gusta ni para ti ni para mí. Palabra. Pero como no quiero ser "poeto", te seguiré llamando "poetisa", que me suena mejor que "poetriz".

(Badosa, 1989: 52)

\footnotetext{
${ }^{4}$ Al respecto, el hispanista Serge Salaün manifestaba "cierta debilidad personal para la palabra 'poetisa', por su eufonía. No pretendo catequizar a nadie". Cf. "Ernestina de Champourcin y Concha Méndez. Estatuto y condición del poeta moderno", en Ernestina de Champourcin. Mujer y cultura en el siglo XX. Rosa Fernández Urtasun y José Ángel Ascunce, eds. Madrid: Biblioteca Nueva, 2006, 40.
} 
No vamos a comentar los diversos valores literarios de este excelente epigrama badosiano, valores entre los que se cuenta una rítmica variada, o la acertadísima asonancia en "oes" del verso seis, de tintes jocosos, o incluso la recuperación irónica del vocablo 'poeto', de cuño unamuniano, según vimos. Nos referiremos tan solo a lo que nos importa aquí, esto es al posicionamiento del escritor ante el empleo de "poeta" en vez de "poetisa".

En primer término, hay que evidenciar dos obviedades: el mero hecho de haber dedicado un poema epigramático a la cuestión, ya indica fehacientemente que estamos ante un problema de actualidad, porque los epigramas se ceban en el presente, no en el ayer ni en el porvenir, y la actualidad a la que se referían tales líneas versales no ha caducado todavía en los comienzos del siglo XXI. Segundo hecho obvio: en todo epigrama subyace una posición normativa desde la cual se satirizan los desvíos, en este caso los del uso lingüístico ordinario. Badosa ha sido siempre celoso y vigilante guardián del que él considera razonablemente mejor empleo idiomático, y sus lectores debemos felicitarle por su atenta y justificada preocupación. Otra cosa es que podamos discrepar sobre algunos aspectos del contenido de sus versos, como explicaré acto seguido.

No estamos de acuerdo, por ejemplo, en que necesariamente haya de achacarse a la ideología feminista el deseo de postergar "poetisa" a favor de "poeta", ni tampoco estamos de acuerdo en que quepa suponer que aquel deseo empareje también una disputa entre gustos terminológicos. Y no estamos conformes porque la mayoría de escritoras que se decantan por "poeta", lo hacen por unas causas bien distintas a las esgrimidas por el autor en él epigrama XXVI de Epigramas confidenciales. Las causas se reducen básicamente a dos: la carga de connotaciones a menudo peyorativas que soporta aún la palabra "poetisa", y la voluntad de desmarcarse de temáticas, de puntos de vista y de actitudes que han sido asociadas a la escritura de las poetas desde el XIX. Por tanto, si la palabra "poeta" no comporta sesgos negativos, entienden que tienen derecho a usarla por lo menos hasta que tampoco los comporte la palabra "poetisa". Y si la voz "poetisa" va ligada inexorablemente a unos temas y perspectivas prefijadas, a modo de espacio o mundo propio de la mujer, entonces la mera recusación del término "poetisa" pretende hacer muy patente que se busca una ruptura con ese condicionamiento.

\section{Razones de una preferencia}

Ricardo Cano Gaviria explicaba muy bien las razones que han llevado a tantas mujeres a preferir el uso de "poeta" como nombre de su actividad de creación literaria en verso. A su entender, en el empleo de "poetisa" se nos está transmitiendo "la imagen de una mujer que es poeta en su registro femenino, entendiendo esto como un uso restringido del oficio de poeta". Añade todavía este crítico que, si tomamos la palabra en un sentido amplio, la poetisa "es una mujer que 'poetiza' ('embelleciéndolos' por medio de la poesía) sobre los temas que se consideran propios de ella".

Y si la palabra se considera restrictivamente, ocurre que poetisa "es simplemente la mujer que escribe poemas cursis". (Cano Gaviria, 1992: 81-82). Extremando esta última concepción restrictiva, a la escritora Pilar Blanco la voz "poetisa" le hacía evocar a las "doncellas lánguidas de corpiño apretado desgranando 
arpegios al claro de luna" 5 , y no extraña tal evocación, porque no hace sino ilustrar imaginativamente el supuesto de la cursilería que siempre acecha al término "poetisa", y que viene de lejos, y no afecta sólo a España, como bien indicaba Ramón Buenaventura:

...a partir del siglo XIX, con el cambio de condiciones sociales se inicia una invasión de lo que entonces llamaban poetisas (palabra que sería muy práctica y que nos facilitaría la vida a todos, pero a la que es forzoso renunciar -como también se ha hecho en inglés- por culpa de las adherencias cursis. (Buenaventura, 1985: 17).

Tales adherencias se quisieron ver igualmente en la poética de los modernistas, a quienes Miguel de Unamuno propuso que se les denominara "poetisos" (Cano Ballesta, 1972: 76), vocablo en el que dejaba traslucir su negativo aprecio del término "poetisa" (Ciplijauskaité, 1966: 143).

Pero no es únicamente cursilería la adherencia que procede eludir, porque hay una lacra peor aún, la del menosprecio hacia la creación poética de las escritoras, según revela un pasaje que se vale de un inconcebible lenguaje de descalificación taxativa:

Poetisas mías, atiendan vuestras mercedes a sus maridos y a sus hijos, mantengan la casa en orden y déjense de versos malos y cochambrosos, que ya hay demasiados poetas que se dedican a ello con terca dedicación (Bejarano, 1992: 39).

Parrafada ayuna de la más mínima autocrítica, en esas líneas son puestas las poetas todas en un mismo saco de deficiencias literarias, imaginándolas casadas y con hijos, y con obligaciones relativas al orden de la casa, mientras deslinda, entre los poetas, a los malos de los que no lo son.

Queda, así pues, justificada con argumentos nada baladíes la opción a favor del vocablo "poeta", y repetimos que hasta que la palabra "poetisa" deje de arrastrar prejuicios que puedan involucrar a las mujeres con unos temas específicos, con una sensibilidad previsible, y siempre bajo un etiquetado poético que se presenta de menor vuelo y significación que el susceptible de acometer y culminar el poeta.

\section{Opciones controversiales del XIX}

El referido posicionamiento en defensa de "poeta" en lugar de "poetisa" no es exclusivo de las poetas españolas de las últimas décadas, porque si retrocedemos en el tiempo se encontrarán reticencias parecidas, aunque acaso no tan rotundas, respecto al uso de "poetisa". Cabe remontar tales reservas incluso a la segunda mitad del siglo XIX, y en concreto a una autora como Rosario Acuña, que desdeñaba, por "feo", que la llamasen "poetisa". Lo decía en los siguientes versos:

\footnotetext{
${ }^{5}$ Véase la entrevista concedida por Pilar Blanco al Diario de León (9 de marzo, 1997). Suplemento "El Filandón", 4.
} 


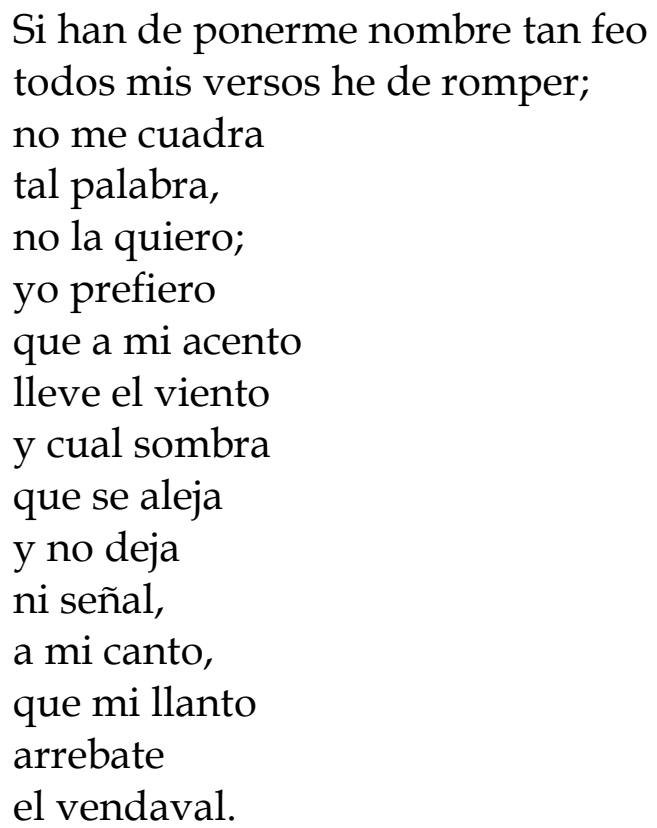

(Urrutia, 1995: 536)

Rechaza Rosario Acuña que la conozcan como poetisa, pero no propone que, en cambio, la llamen poeta. Que no le pongan nombre alguno es su deseo. Imaginamos, aunque no lo aclara, que la fealdad del término "poetisa" no está en la palabra como composición material, sino en los conceptos negativos vinculados a ella, conceptos que igualmente debieron pesar, en sentido negativo, a Rosalía de Castro al hacer referencia al vocablo asegurando, en 1865, que "(esta palabra ya llegó a hacerme daño)" (Quance, 1987: 79).

Frente a esta renuncia de Rosario Acuña a que la tilden de poetisa, a mediados del XIX nos encontramos, empero, con una defensa contundente, por parte de Carolina Coronado, de la aplicación de la palabra "poetisa" a las poetas. Dicha defensa se llevó a cabo en dos artículos publicados en La discusión, y ambos bajo el título de "Galería de poetisas contemporáneas: doña Gertrudis Gómez de Avellaneda". La fecha de los dos artículos fue, respectivamente, 5 de agosto de 1857, y 29 de mayo de 1858.

Carolina Coronado defendió la voz "poetisa" a vueltas de que Ferrer del Río se la negaba a la antillana Gertrudis Gómez de Avellaneda. Ferrer del Río, en efecto, había declarado literalmente: "No es la Avellaneda poetisa, sino poeta". ¿En base a qué? Pues fundándose en que veía voz y carácter masculino en el verso de la autora cubana, la cual también llegó a creerse el dictamen de que la caracterizaba la masculinidad, y actuó en una ocasión en consecuencia, poniéndose nombre masculino para ganar un concurso literario.

Deplora la Coronado en la Avellaneda que tomase la decisión de camuflar su nombre de mujer por otro de hombre, pero deplora más todavía que algunos hombres de su época hayan querido engrosar la nómina de poetas varones añadiendo a una mujer entre ellos mediante el metamorfoseo del concepto de poetisa en el de poeta. Su argumentación, al respecto, es tan persuasiva como contundente: 
Después de tantos siglos de esperar la aparición de un astro donde la luz de Safo se reflejase, cuando del centro del océano aparece vivo, reluciente, espléndido, radioso, ¿nos le quieren quitar de nuestro cielo? Los otros hombres del tiempo antiguo negaban el genio de la mujer; hoy los del moderno, ya que no pueden negar al que triunfa, lo metamorfosean (Coronado, 1999: 189).

A continuación señala que, por el mismo criterio que a una mujer con voz poética vigorosa y fuerte, se la ha puesto en la fila de los hombres, a los hombres de registro tenue y delicado habría que ponerlos en la lista de las mujeres, y nadie lo hace, lo que demuestra que esta vía resulta inadecuada, y por tanto la declaración de Ferrer del Río no es más que un abusivo ataque encubierto a las mujeres que escriben poesía, ya que vitupera el nombre de "poetisa" para una que sobresale -bizarramente- en el menester de la composición de versos.

Para Carolina Coronado, la causa de que se haya pretendido alinear a la Avellaneda entre los hombres que hacen versos, separándola de las mujeres, no es otra que la errónea calificación del ingenio humano en masculino o femenino, apoyándose en el "tono" de la voz poética de la mujer. Acto seguido, y con una argumentación de gran modernidad, añade que "Como hay flores sencillas y flores dobles, hallo que algunos ingenios tienen la doble facultad concedida a los dos sexos". (Coronado, 1999: 190-191). Es decir: tanto una mujer como un hombre pueden tener una voz lírica robusta, o tenerla delicada, pero no por ello ha de dejar de predicarse el nombre de "poetisa" de las mujeres que hacen poesía.

Frente a razonamientos como los de Coronado, sorprende un tanto que Emilia Pardo Bazán suscribiese posiciones como las de Ferrer del Río, negándole a Rosalía de Castro el nombre de "poetisa", que por lo demás tampoco gustaba a la autora de Padrón, para otorgarle el de "poeta" en su acepción más masculinista, y aun de "poeta verdadero". Lo llamativo en este punto de vista es su creencia de que a una mujer no le es dado componer "buena" poesía, de modo que la importancia literaria de la escritura poética rosaliana se basaría justamente en que logró alcanzar los altos vuelos del escritor-poeta, inalcanzables para una escritora-poetisa. (Reisz, 1996: 42).

\section{Apunte final}

Hasta aquí algunas reflexiones y posicionamientos en torno al polémico empleo de "poetisa" o "poeta" para mencionar la dedicación de las mujeres a la creación poética. Parece justificado el rechazo del uso de "poetisa" por parte de no pocas autoras, pero el reconocimiento creciente de la gran importancia de la aportación de la mujer a la poesía, acaso acabe descargando definitivamente de valores negativos y de inferioridad al término "poetisa", valores éstos que incluso sustentaron personalidades tan preclaras como Octavio Paz, a quien, en el prólogo al primer libro de Blanca Varela, no se le ocurrió nada mejor, para alabarla, que decir que era "nada más y nada menos, un poeta, un verdadero poeta". (Reisz, 1996: 42) 
En el siglo XXI imaginamos que irá perdiendo más y más adeptos una opinión convergente con las citadas de Ferrer del Río, de Emilia Pardo Bazán y de Octavio Paz, entre tantas otras, a vueltas de la progresiva constatación del valor de la poesía escrita por mujeres, amén de dejar de asociarse a valores tan aleatorios como los que derivan de la bipolarización tradicional entre lo masculino y lo femenino.

Si así fuese, la palabra "poetisa" podría -y puede que debiera- volver a generalizarse, toda vez que su uso es reivindicado asimismo por no pocas autoras que defienden una especificidad propia en las perspectivas y en la escritura de la mujer, una especificidad intrínseca y alternativa a los textos que han predominado durante siglos. 